\title{
Author Correction: ID3 regulates the MDC1- mediated DNA damage response in order to maintain genome stability
}

Jung-Hee Lee ${ }^{1,2}$, Seon-Joo Park¹,3, Gurusamy Hariharasudhan¹, Min-Ji Kim¹, Sung Mi Jung1, Seo-Yeon Jeong ${ }^{1,2}$, In-Youb Chang ${ }^{4}$, Cheolhee Kim ${ }^{5}$, Eunae Kim (1) ${ }^{5}$, Jihyeon Yu ${ }^{6}$, Sangsu Bae ${ }^{6} \&$ Ho Jin You ${ }^{1,7}$

Correction to: Nature Communications https://doi.org/10.1038/s41467-017-01051-z, published online 12 October 2017

This Article contains errors in Figs. 3, 4 and 7, for which we apologize. In Fig. 3, panel 'b', the 0.5 h time point after Ku55933 treatment images were inadvertently replaced with duplicates of the $3 \mathrm{~h}$ time point after Ku55933 treatment images in Fig. $3 \mathrm{~b}$. Additionally, in panel ' $b$ ', the $0.5 \mathrm{~h}$ time point after Nu7026 treatment images were inadvertently replaced with duplicates of the 180 min time point after siMDC1 treatment images in Fig. 3d. The correct version of this figure appears below as Fig. 1. The raw data associated with this experiment are provided as a separate Supplementary Data 1 file.

\footnotetext{
${ }^{1}$ Laboratory of Genomic Instability and Cancer Therapeutics, Cancer Mutation Research Center, Chosun University School of Medicine, Gwangju 501-759, Republic of Korea. ${ }^{2}$ Department of Cellular and Molecular Medicine, Chosun University School of Medicine, Gwangju 501-759, Republic of Korea.

${ }^{3}$ Department of Premedical Sciences, Chosun University School of Medicine, Gwangju 501-759, Republic of Korea. ${ }^{4}$ Department of Anatomy, Chosun University School of Medicine, Gwangju 501-759, Republic of Korea. ${ }^{5}$ College of Pharmacy, Chosun University, 375 Seosuk-dong, Gwangju 501-759, Republic of Korea. ${ }^{6}$ Department of Chemistry, Hanyang University, Seoul 04763, Republic of Korea. ${ }^{7}$ Department of Pharmacology, Chosun University School of Medicine, Gwangju 501-759, Republic of Korea. Correspondence and requests for materials should be addressed to J.-H.L. (email: jhlee75@chosun.ac.kr) or to H.J.Y. (email: hjyou@chosun.ac.kr)
} 

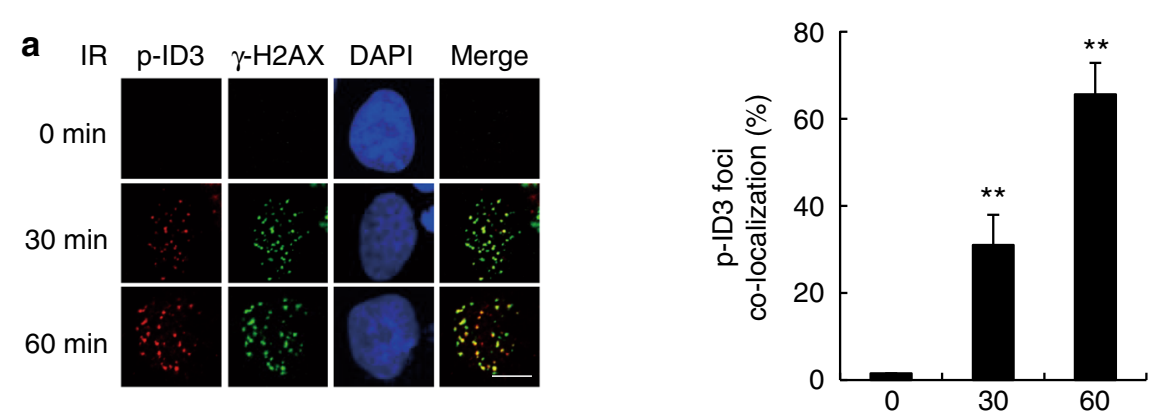

Minutes post IR (2 Gy) treatment
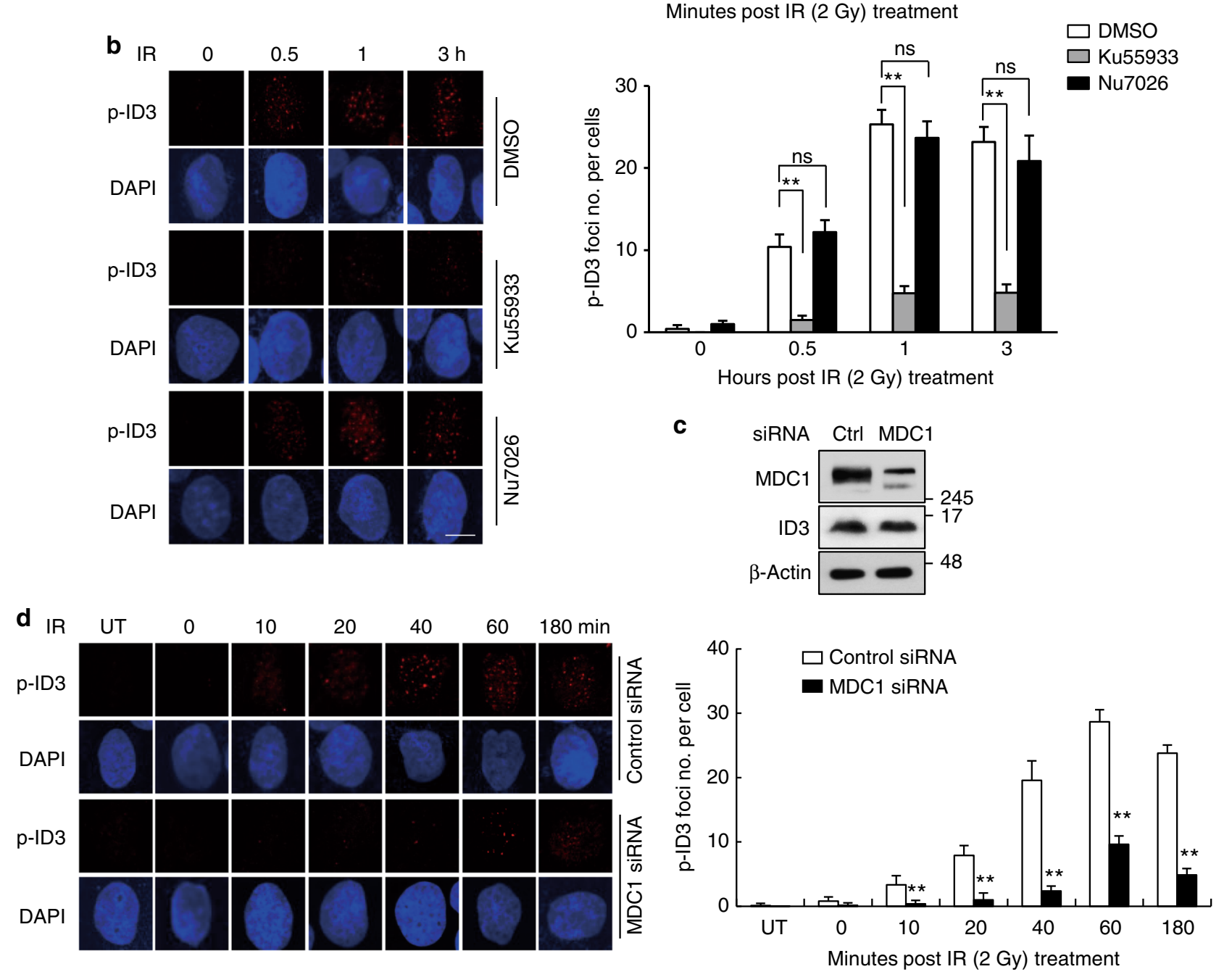

Fig. 1 . 
In Fig. 4, panel 'g', RNF168 foci in U2OS cell images were inadvertently replaced with duplicates of RNF168 foci in HeLa cell images in Fig. 4f. The correct version of this figure appears below as Fig. 2. The raw data associated with this experiment are provided as a separate Supplementary Data 2 file.

a

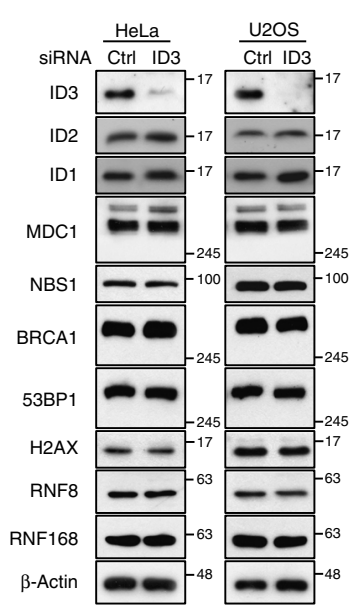

$\begin{array}{llllllllll}\text { b } & \text { IR } & \text { UT } & 0 & 10 & 20 & 40 & 60 & 180 \text { Min HeLa }\end{array}$

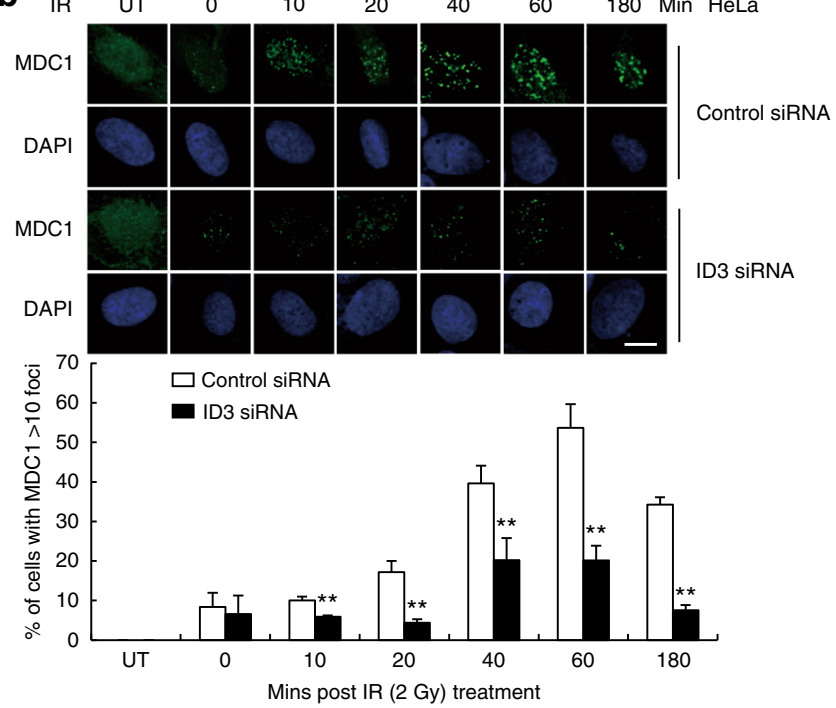

C
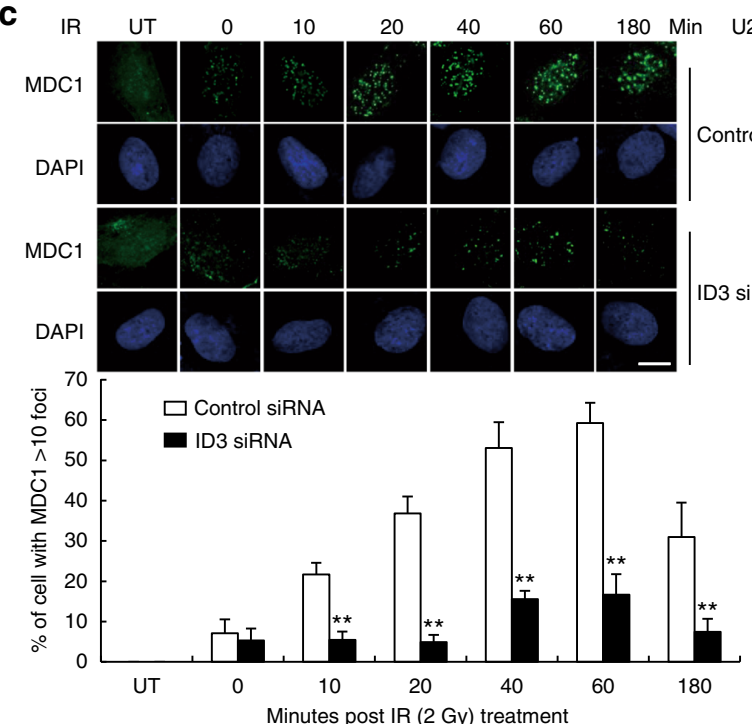

f
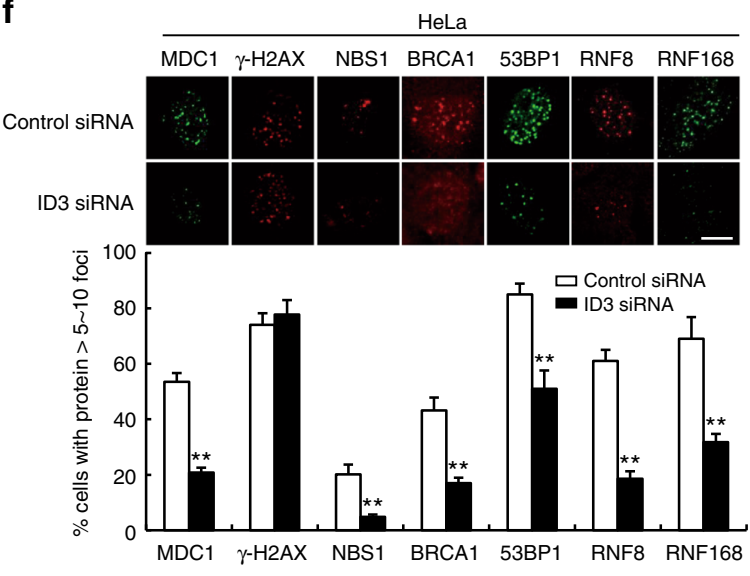

1 hour post IR (2 Gy) treatment

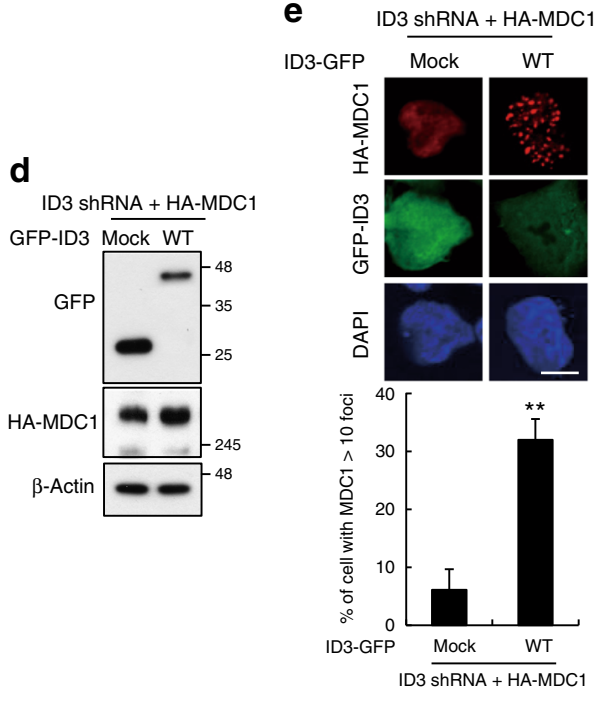

g

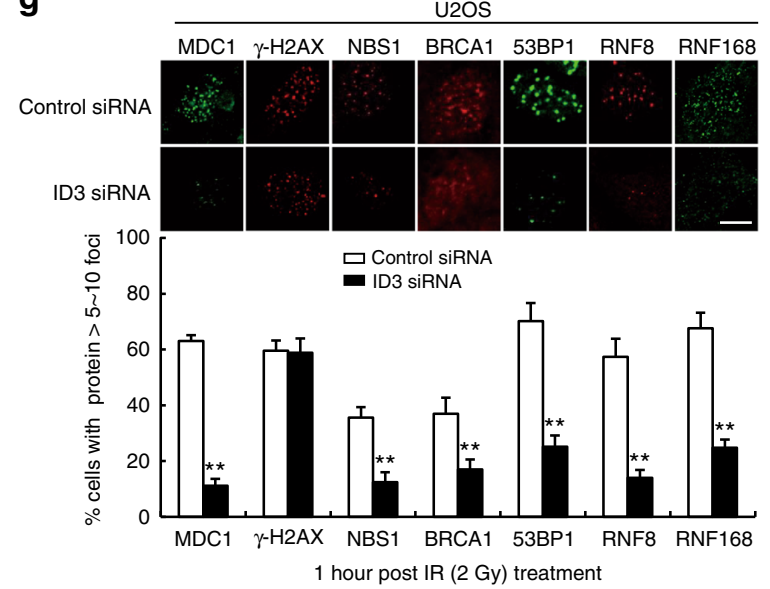

Fig. 2 . 
In Fig. 7, panel 'b', the DAPI images $0.5 \mathrm{~h}$ after IR under siID3 treatment were inadvertently replaced with DAPI images of a different field of view from the same experiment. Additionally, in panel ' $i$ ', the shID3 mock-treated GFP-ID3 cells image was inadvertently replace with duplications of the shID3 mock-treated GFP-ID3 cells image in Fig. $7 \mathrm{~g}$. The correct version of this figure appears below as Fig. 3. The raw data associated with this experiment are provided as a separate Supplementary Data 3 file.

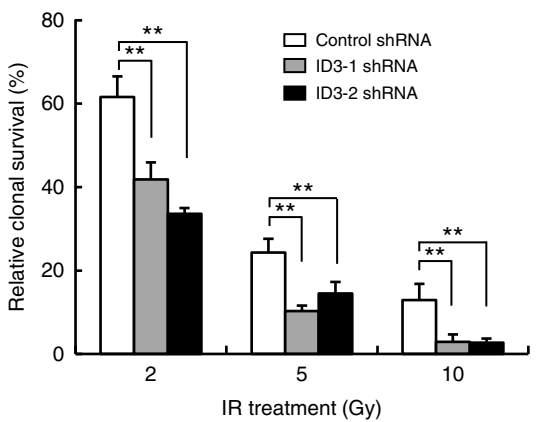

d

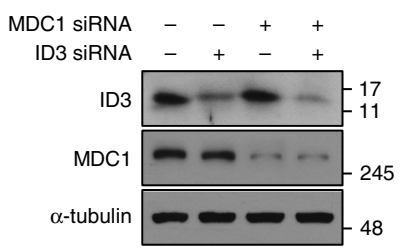

e

MDC1 siRNA ID3 siRNA
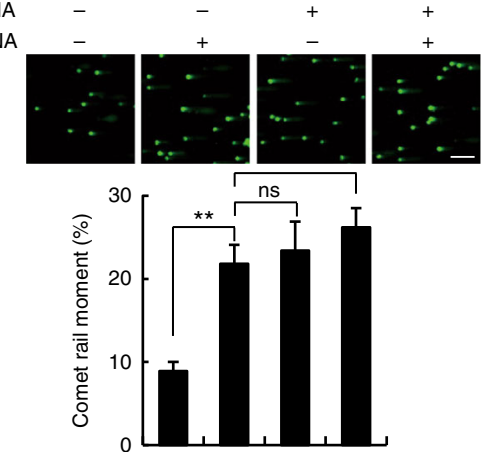

MDC1 SiRNA

D3 $\operatorname{sinNA}$
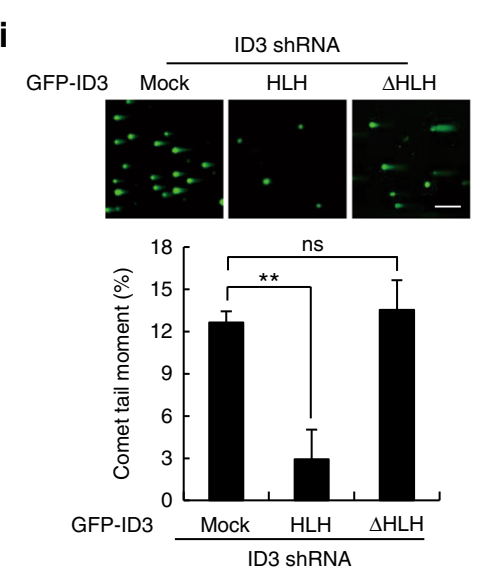

j

\section{b}
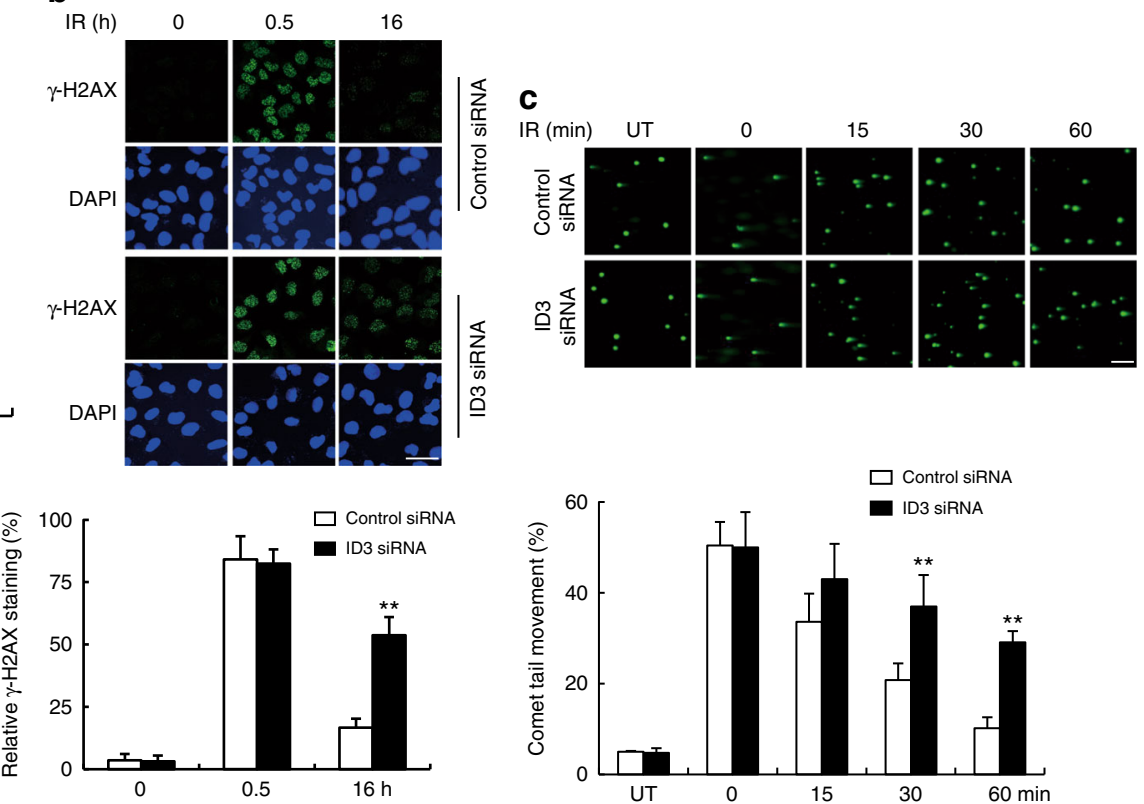

f

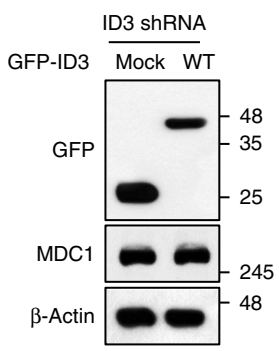

g
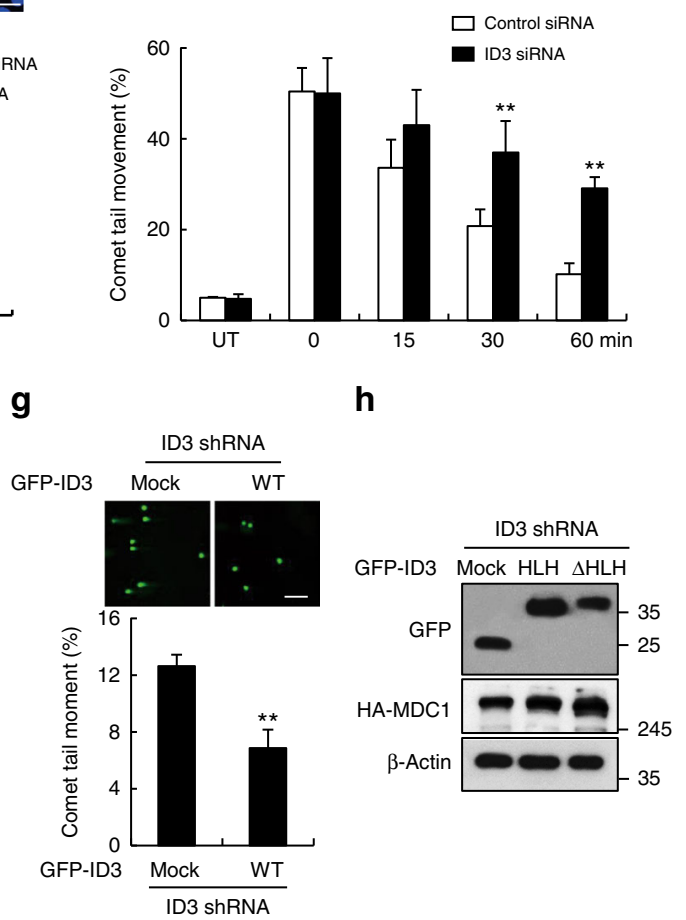

h

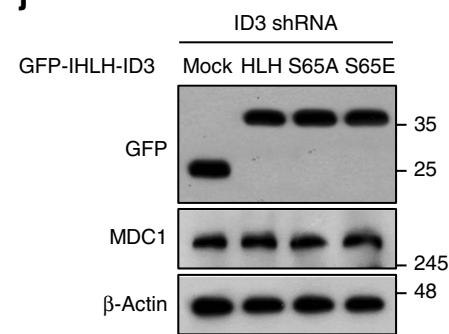

$\mathbf{K}$
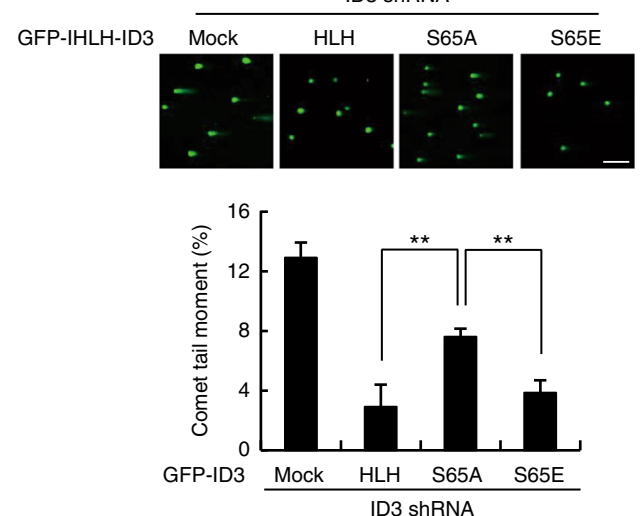

Fig. 3 
(c) Open Access This article is licensed under a Creative Commons Attribution 4.0 International License, which permits use, sharing, adaptation, distribution and reproduction in any medium or format, as long as you give appropriate credit to the original author(s) and the source, provide a link to the Creative Commons license, and indicate if changes were made. The images or other third party material in this article are included in the article's Creative Commons license, unless indicated otherwise in a credit line to the material. If material is not included in the article's Creative Commons license and your intended use is not permitted by statutory regulation or exceeds the permitted use, you will need to obtain permission directly from the copyright holder. To view a copy of this license, visit http://creativecommons.org/licenses/by/4.0/.

(c) The Author(s) 2018 